\title{
Jugando a las escondidas
}

\section{Playing Hide and Seek}

\author{
L. García ${ }^{1} \quad$ C. Afione ${ }^{1}$ \\ ${ }^{1}$ Sanatorio Güemes, Ciudad Autónoma de Buenos Aires, Argentina \\ Rev Argent Radiol 2019;83:136.
}

Paciente masculino de 30 años de edad, con antecedente de esguince de tobillo. Se realizó resonancia magnética (RM) para su evaluación.

En uno de los cortes del plano coronal en secuencia STIR ( -Fig. 1A), se visualiza una imagen que remeda un rostro masculino oculta en la articulación del tobillo. El rostro se
Address for correspondence L. García, MD, Sanatorio Güemes, Ciudad Autónoma de Buenos Aires, Argentina (e-mail: laugarcia48@hotmail.com).

encuentra representado por el volumen parcial de la articulación tibio-peroneo-astragalina, el ligamento peroneo-astragalino posterior y líquido articular.

Como mencionara Irvin Kershner, "No hay nada más interesante que el paisaje del rostro humano" (-Fig. 1B).
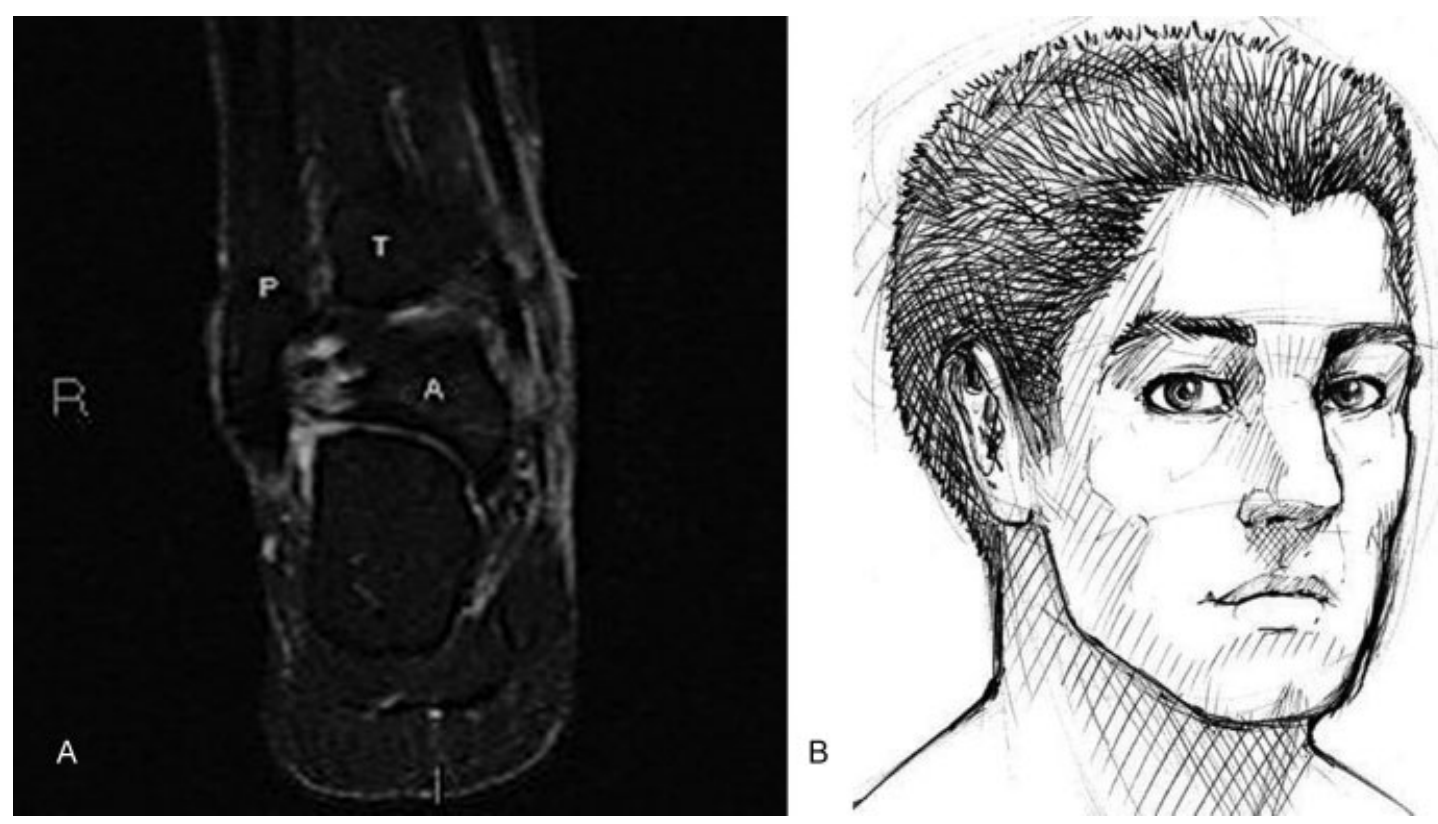

Fig. 1 Imagen en secuencia STIR en plano coronal donde: (A) se observa imagen que remeda un rostro masculino conformado por el volumen parcial de la articulación tibio-peroneo-astragalina, líquido articular y el ligamento peroneo-astragalino posterior. T: tibia. P: peroné. A: astrágalo y (B) dibujo de un rostro humano.

received

September 13, 2017

accepted

November 12, 2017
DOI https://doi.org/

$10.1055 / \mathrm{s}-0038-1639464$.

ISSN 1852-9992.
Copyright (c) 2019, Sociedad Argentina de Radiología. Publicado por Thieme Revinter Publicações Ltda., Rio de Janeiro, Brazil. Todos los derechos reservados.

\section{License terms}

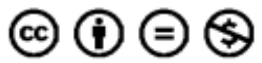

